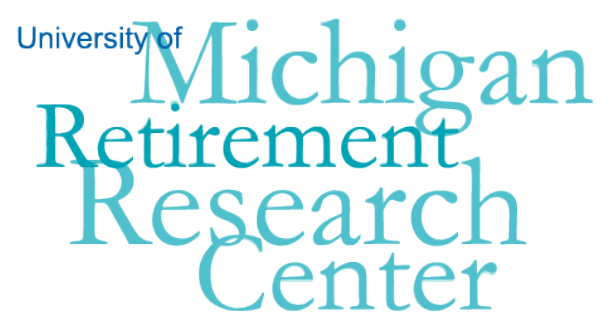

Working Paper WP 2013-280

\title{
Technological Progress and the Earnings of Older Workers
}

Yuriy Gorodnichenko, John Laitner, Jae Song and Dmitriy Stolyarov

\begin{tabular}{|l|l|}
\hline $\mathrm{M}$ & $\mathrm{R}$ \\
\hline $\mathrm{R}$ & $\mathrm{C}$ \\
\hline
\end{tabular}

Project \#: UM12-01 



\title{
Technological Progress and the Earnings of Older Workers
}

\author{
Yuriy Gorodnichenko \\ University of California - Berkley \\ John Laitner \\ University of Michigan \\ Jae Song \\ Social Security Administration \\ Dmitriy Stolyarov \\ University of Michigan
}

October 2013

\author{
Michigan Retirement Research Center \\ University of Michigan \\ P.O. Box 1248 \\ Ann Arbor, MI 48104 \\ www.mrrc.isr.umich.edu \\ (734) 615-0422
}

\section{Acknowledgements}

This work was supported by a grant from the Social Security Administration through the Michigan Retirement Research Center (Grant \# 5 RRC08098401-04-00). The findings and conclusions expressed are solely those of the author and do not represent the views of the Social Security Administration, any agency of the Federal government, or the Michigan Retirement Research Center. 


\title{
Technological Progress and the Earnings of Older Workers
}

\begin{abstract}
Economists' standard model assumes that improvements in total factor productivity (TFP) raise the marginal product of labor for all workers evenly. This paper uses an earnings dynamics regression model to study whether, in practice, older workers benefit less from TFP growth than younger workers. We utilize panel earnings data from the Social Security Administration's Continuous Work History Sample. The data include workers of all ages, and we use annual figures for 1950-2004. Our first specification relies on BLS measurements of TFP. Our second model develops a new TFP measure using a principal components analysis. We find that although the earnings of younger workers track TFP growth 1-for-1, the earnings of older workers do not: we find, for example, that a 60-year-old male's earnings grow only $85-90 \%$ as fast as TFP. Nevertheless, our analysis implies that in an economy with an aging labor force, gains from experience tend to outweigh older workers' inability to benefit fully from TFP improvements.
\end{abstract}

\section{Citation}

Gorodnichenko, Yuriy, John Laitner, Jae Song, and Dmitriy Stolyarov (2013). "Technological Progress and the Earnings of Older Workers.” Ann Arbor MI: University of Michigan Retirement Research Center (MRRC) Working Paper, WP 2013-280. http://www.mrrc.isr.umich.edu/publications/papers/pdf/wp280.pdf 


\title{
Technological Progress and the Earnings of Older Workers
}

\author{
Yuriy Gorodnichenko, John Laitner, Jae Song, and Dmitriy Stolyarov
}

1 Introduction. This paper examines whether the earnings of older US workers track overall increases in TFP as comprehensively as those of their younger colleagues. The US population is aging: longevity is increasing, while fertility is, if anything, trending in the opposite direction. If the marginal product of younger workers rises proportionately with TFP but the marginal product of older workers lags behind, then innovation will, in effect, tend to diffuse more slowly as the labor force ages. Retirement timing may be influenced as well. In general, as longevity rises, we expect both work lives and retirement spans to increase. Workers' optimal allocations of extra years of life between career and retirement will, however, be sensitive to the rate of pay available. In fact, we find that the pay of older US employees does not follow TFP growth as closely as the remuneration of younger workers - though the difference is, perhaps, surprisingly small - and we attempt to provide quantitative assessments of the likely impact on the economy.

We use an earnings dynamics model. A large literature provides estimates of such models (e.g., Lillard and Willis [1978], Lillard and Weiss [1979], Hause [1980], and MaCurdy [1882], as well as more recent work by Baker [1997], Haider [2001], Baker and Solon [2003], Guvenen [2007], Altonji et al. [2009], and many others). In a typical specification, a worker's wage, or earnings, at age $s$ and time $t$, say, $w_{s t}$, rises with experience and time:

$$
\ln \left(w_{s t}\right)=\phi(s)+\psi(s, t) .
$$

The first right-hand side term captures the effect of human capital. Human capital typically rises with experience, hence, with age; thus, in the case of younger workers, we expect $\phi^{\prime}(s)>0$. At older ages, on the other hand, declining health and/or depreciation of human capital might cause $\phi^{\prime}(s)<0$.

The second right-hand side term registers the effect of growth in overall total factor productivity (TFP). Following Solow [1956], we expect $\partial \psi(s, t) / \partial t>0$. The earnings dynamics literature normally assumes that the influence of TFP is independent of a worker's age - that is to say, it posits

$$
\frac{\partial \psi(s, t)}{\partial t}>0 \quad \text { and } \quad \psi(s, t)=\psi^{1}(t) .
$$

This paper investigates the alternative possibility that

$$
\frac{\partial \psi(s, t)}{\partial t}>0 \quad \text { but } \quad \frac{\partial^{2} \psi(s, t)}{\partial s \partial t}<0 .
$$


We have access to an unusually rich set of data on worker earnings, by age, 19502004, the Social Security Administration's Continuous Work History Sample (CWHS). ${ }^{1,2}$ The data provides panel earnings from administrative records, for thousands of workers, providing many observations at each age, in every year. Alternative data sources such as the CPS or PSID lack coverage during the 1950s and early 1960s. ${ }^{3}$ To identify our model and to estimate its parameters precisely, we need TFP growth rates to vary within sample. That makes the 1950s and 1960s — when TFP growth was unusually rapid (what Field [2011], for example, calls the "golden age of US productivity growth") - especially important. ${ }^{4}$ We use the CWHS data to estimate our version of (1), focusing on the second part of condition (3).

Our results show that the earnings of aging workers do not grow one-for-one with TFP but that the difference is quite modest. Our best results imply that the earnings of a 60 year old follow TFP growth 85-90 percent as well as those of a 26-30 year old. About one half of the decline seems to run its course by age 45 . In the end, the greater experiential human capital of older workers seems to outweigh their declining linkage to the TFP level - see Section 6. Hence, an aging labor force should be a more productive one.

The organization of this paper is as follows. Section 2 suggests possible reasons for inequality (3). Section 3 presents our theoretical framework. Section 4 describes our data. Section 5 presents two empirical specifications of our model and regression results for each. Section 6 examines the implications of the results for the US economy. Section 7 concludes.

2 Possible Outcomes. What outcome do we expect?

Four possibilities are as follows.

A1: The arrival of a new technology should affect workers at the start of their careers the most. At the beginning of a career, we expect a worker to make a large investment in learning about the current techology because the payoff period is long. Near retirement, the reverse holds. Thus, an optimal life-cycle investment pattern should lead to a younger worker having a marginal product of labor reflecting the best current technology, but the same may not hold for older workers.

"Creative destruction" provides a related interpretation. Suppose, for example, that learning how to use a new technology yields revenue $R_{1}$ to a young worker but costs the worker $C_{1}$. If $R_{1}-C_{1}>0$, learning the new skill is profitable. An older worker may, however, have completed such a process in the past, gaining $R_{0}-C_{0}>0$. If revenues $R_{00}$ from the older technology remain (without further cost) but must be sacrificed upon substitution of the new technology, the older worker should only invest in the new skill if $R_{1}-C_{1}>R_{00}$.

1 See, for example, Kopczuk, Saez and Song [2010].

2 Actually, the data runs 1937-2004. To avoid WWII - and because standard BLS TFP measurements begin in 1948 — we limit our analysis to 1950-2004.

3 See, for instance, Laitner and Stolyarov [2005].

4 Field [2011, Tab. 3.6] presents cyclically adjusted TFP annual growth rates for the US private nonfarm economy showing 1.90 for 1948-1973, 0.34 for 1973-1989, and 0.78 for 1989-2000. 
A variety of manifestations of the effect of TFP growth are possible. In an extreme variant, a worker will devote full-time effort to investing in learning prior to beginning his career, but he will discontinue investment subsequently. This will create circumstances analogous to Solow's [1960] model of embodied technological progress: although the marginal productivity of young workers will reflect the best current technology, the knowledge of older workers will progressively become obsolete. Obsolescence should be more dramatic when TFP growth is high.

Alternatively, on-the-job training to keep up with continuous technology improvements might be the rule — see, for example, Ben-Porath [1967]. At each age, a worker might make an optimal time allocation between production and learning. As retirement approaches, the optimal allocation might shift to less time spent learning and more on production. In practice, workers might stay up-to-date until the last handful of years before retirement.

A2: A physiological consequence of aging may be that older individuals are less adaptable to learning new ways of performing tasks. Hence, older workers may be unable to benefit as easily as the young from TFP growth.

A3: Regardless of age, different people may have different ability to absorb new information and develop ways to take advantage of it. Within a business, some individuals may specialize in recognizing, learning, and adapting new technologies. They may organize the work of others. On the other hand, a majority of workers may not need to be especially good at adopting new technologies - and there may be little reason to expect that age is an especially important factor.

A4: Workers and firms may agree to (implicit) long-term contracts in which the worker is paid less than his marginal product at first but more later (see, for example, Lazear $[1979,1981])$. This system may leave firms with little latitude to respond to unforeseen changes in TFP, whether changes affect different age groups differently or not. Similarly, implicit contracts may promote risk sharing in which the firm absorbs fluctuations resulting from uneven technological progress.

Note that answers A1-A2 seem to raise the possibility of selection processes in the data. It seems possible, for example, that workers who face obsolescence from rapid TFP growth tend to choose early retirement. In practice, the issue may be complicated, however. If obsolescence is predictable, then a life-cycle household might plan for early retirement, doing a great deal of saving in youth. But if obsolescence is random, a victimized household might need to extend its career in order to accumulate enough resources for a comfortable retirement. In theory, therefore, a household's retirement age could either rise or fall with a change in TFP.

3 Model. As stated, we develop 2 variants of our regression model. This section presents the basic theoretical framework common to both.

Our analysis is limited to working males. ${ }^{5}$ Consider male $i$ of age $s$ at time $t$. His

${ }^{5}$ Changes in female labor-force participation (especially, the participation of married women) during our sample period - for reasons different from the central concerns of this paper - are well-known. 
wage is $w_{i s t}{ }^{6}$ The latter depends on individual ability, $\xi_{i}$; human capital; $H_{i s}$; technological progress; and, the wage rate per efficiency unit of labor, $w_{t}^{E}$. Let $L_{t}^{Q}$ be labor input corrected for human capital (i.e., experience and education) and gender. Let $T_{t}$ be aggregative total factor productivity (TFP). If $Y_{t}$ is output and $K_{t}$ the physical capital stock, assume ${ }^{7}$

$$
Y_{t}=T_{t} \cdot\left[K_{t}\right]^{\alpha} \cdot\left[L_{t}^{Q}\right]^{1-\alpha}, \quad \alpha \in(0,1) .
$$

If $E_{t}$ is labor input measured in effective units,

$$
\begin{aligned}
Y_{t} & =\left[K_{t}\right]^{\alpha} \cdot\left[E_{t}\right]^{1-\alpha} \\
& \equiv\left[K_{t}\right]^{\alpha} \cdot\left[T_{t}^{\frac{1}{1-\alpha}} \cdot L_{t}^{Q}\right]^{1-\alpha} .
\end{aligned}
$$

Let

$$
w_{t}^{E}=\frac{\partial Y_{t}}{\partial E_{t}}
$$

Suppose at a base age, say, 25, all workers can benefit fully from TFP growth. Then set $S=S(s) \equiv s-24$, so that $S$ measures career years since the base age, starting with $S=1$ at the base age. Assume

$$
w_{i s t}=\xi_{i} \cdot H_{i s} \cdot\left[T_{t-S}\right]^{\frac{1}{1-\alpha}} \cdot\left[\frac{T_{t-S+1}}{T_{t-S}}\right]^{\frac{\theta_{1}}{1-\alpha}} \cdot \ldots \cdot\left[\frac{T_{t}}{T_{t-1}}\right]^{\frac{\theta_{S}}{1-\alpha}} \cdot w_{t}^{E}
$$

If workers of all ages benefit fully from technological progress, we have

$$
\theta_{x}=1 \quad \text { all } \quad x=1, \ldots, S
$$

Then

$$
w_{i s t}=\xi_{i} \cdot H_{i s} \cdot\left[T_{t}\right]^{\frac{1}{1-\alpha}} \cdot w_{t}^{E} .
$$

Section 2 suggests, however, the possibility that

$$
1 \geq \theta_{1} \geq \ldots \geq \theta_{S}
$$

6 Because of data availability, the empirical analysis depends upon earnings rather than wage rates. See the discussion in Section 4 below.

7 Rather than write the production function as

$$
A \cdot\left[K_{t}\right]^{\alpha_{t}} \cdot\left[L_{t}^{Q}\right]^{1-\alpha_{t}},
$$

we have included $A$ in $L_{t}^{Q}$. 
If some of the inequalities in (8) are strict, older workers benefit from technological progress less than younger workers.

Use the notation

$$
\Delta \ln \left(w_{i s t}\right) \equiv \ln \left(w_{i s t}\right)-\ln \left(w_{i, s-1, t-1}\right) .
$$

Let

$$
T_{t}^{*} \equiv\left[T_{t}\right]^{\frac{1}{1-\alpha}} \quad \text { and } \quad \Delta \ln \left(T_{t}^{*}\right)=\ln \left(T_{t}^{*}\right)-\ln \left(T_{t-1}^{*}\right) .
$$

Similarly, let

$$
\Delta \ln \left(H_{i s}\right)=\ln \left(H_{i s}\right)-\ln \left(H_{i, s-1}\right) .
$$

Then (7) implies

$$
\Delta \ln \left(w_{i s t}\right)=\Delta \ln \left(H_{i s}\right)+\theta_{S(s)} \cdot \Delta \ln \left(T_{t}^{*}\right)+\Delta \ln \left(w_{t}^{E}\right) .
$$

We assume that the human capital term, $\Delta \ln \left(H_{i s}\right)$, originates from a combination of schooling and experience at work. We consider several possible formulations.

The first follows most of the earnings dynamics literature in modeling $\ln \left(H_{i s}\right)$ with a polynomial in years of work experience, $x$, with coefficients depending upon the schooling of individual in question. We expect the polynomial to rise at low levels of experience, and to level off or fall at high levels.

Consider 4 education categories:

$$
\mathcal{E} \equiv\{\text { less than high school, high school, some college, college }\} \text {. }
$$

Let $\operatorname{school}(e)$ give the average number of years of schooling in category $e \in \mathcal{E}$. Assume that if worker $i$ has education $e=e_{i}$, then

$$
x=x\left(s, e_{i}\right) \equiv s-\operatorname{school}\left(e_{i}\right)-6 .
$$

If we use a quadratic, ${ }^{8}$

$$
\ln \left(H_{i s}\right)=p_{0}\left(e_{i}\right)+p_{1}\left(e_{i}\right) \cdot x\left(s, e_{i}\right)+\frac{p_{2}\left(e_{i}\right)}{2} \cdot\left[x\left(s, e_{i}\right)\right]^{2} .
$$

Then

$$
\Delta \ln \left(H_{i s}\right)= \begin{cases}p_{1}\left(e_{i}\right)+\left[p_{2}\left(e_{i}\right) / 2\right] \cdot\left[2 \cdot x\left(s, e_{i}\right)-1\right], & \text { for } x\left(s, e_{i}\right) \geq 1, \\ 0, & \text { otherwise } .\end{cases}
$$

We expect

8 The earnings dynamics literature sometimes favors a quartic. A quartic would not fundamentally change our analysis below. 


$$
p_{1}(e)>0 \text { and } p_{2}(e)<0 \text { all } e \in \mathcal{E} \text {. }
$$

The second formulation is a streamlined version of the first. We work exclusively with differenced data; hence, the influence of education on the level of a worker's earnings, that is to say, the parameter $p_{0}(e)$, never enters our analysis. Anticipating that remaining effects of education may be subtle, the second formulation imposes

$$
p_{1}(e)=\overline{p_{1}} \quad \text { and } \quad p_{2}(e)=\overline{p_{2}} \quad \text { all } \quad e \in \mathcal{E} .
$$

In place of (11), we have

$$
\Delta \ln \left(H_{i s}\right)= \begin{cases}\overline{p_{1}}+\left[\overline{p_{2}} / 2\right] \cdot\left[2 \cdot x\left(s, e_{i}\right)-1\right], & \text { for } x\left(s, e_{i}\right) \geq 1, \\ 0, & \text { otherwise } .\end{cases}
$$

The third formulation continues to employ $\overline{p_{1}}$ and $\overline{p_{2}}$, but it uses age, $s$, in place of experience, $x$. Then

$$
\Delta \ln \left(H_{i s}\right)=\overline{p_{1}}+\left[\overline{p_{2}} / 2\right] \cdot[2 \cdot s-1] .
$$

In practice, workers of a given age who have less schooling will tend to have more years of work experience. A possible justification for (14), nevertheless, is that more of the early career years of the less educated may be spent on apprenticeships than would be the case for, say, university graduates.

Finally, from (5)-(6),

$$
w_{t}^{E}=(1-\alpha) \cdot \frac{Y_{t}}{E_{t}}=(1-\alpha) \cdot\left[\frac{K_{t}}{E_{t}}\right]^{\alpha}=(1-\alpha) \cdot\left[\frac{K_{t}}{Y_{t}}\right]^{\frac{\alpha}{1-\alpha}} .
$$

4 Data. We use data from 3 sources: administrative panel data from SSA on individual workers' year-by-year earnings, Census data on worker education by year and age, and BLS data on wages per efficiency unit of labor and TFP growth.

SSA data on workers' earnings. With generous cooperation from SSA, we have obtained access to administrative panel data on worker earnings — classified by age, year, sex, and race. ${ }^{9}$

The data come from the 1\% CWHS 1951-2004; the LEED 1957-2004 (which provides employer information); and, the 0.1\% CWHS 1937-1977. See Kopczuk et al. [2010] and Kopczuk et al. Web Appendix. Kopczuk et al. [2010] utilize earnings estimates above the Social Security tax cap for years prior to 1978 (after 1978, W2 data becomes available). ${ }^{10}$

9 A number of studies compare administrative records with survey measures - e.g., Haider and Solon [2006], Bound et al. [2001], Moore et al. [1997], and Bound and Krueger [1991].

10 The earnings estimates prior to 1978 utilize information on the quarter in which a worker reached the tax cap. 
Kopczuk et al. provide occupational filters to correct for poorly represented groups in early years (see Kopczuk et al. Web Appendix); and, they correct for coding errors 1978-1980. With the assistance of SSA, we have been able to take advantage of all of these steps.

We have obtained access to log earnings figures for all males, and all white males, averaged for age/year cells $(s, t), s=24, \ldots, 75, t=1949, \ldots, 2004$. Call a cell's average value

$$
\widetilde{\ln \left(w_{s t}\right)} \text {. }
$$

The data set does not include work hours. We employ 3 filters to minimize the effect of part-time work, especially part-time work near retirement. We can also adjust the ages at which our sample starts and stops. The filters are:

- Use minimum wages from http://www.ssa.gov/policy/docs/statcomps/supplement/, Table 3.B3, col. 1, to exclude $w_{i s t}$ if

$$
w_{i s t}<1800 \times \min \text { wage year } t \text {. }
$$

- Let last $_{i}$ be the minimum of the last age male $i$ is alive and the last age at which male $i$ has positive earnings. Then drop $w_{i s t}$ if $s \geq$ last $_{i}-1$.

- We work below with $\log$ differences: $\Delta \ln \left(w_{i s t}\right) \equiv \ln \left(w_{i s t}\right)-\ln \left(w_{i, s-1, t-1}\right)$. When the actual difference is positive, set $\Delta \ln \left(w_{i s t}\right)$ equal to the minimum of the actual difference and 1 . When the actual difference is negative, use the maximum of the actual difference and -1 .

Given the filters, we treat our Social Security earnings as perfectly collinear with wages.

The Social Security tax base (and, hence, our earnings data) excludes fringe benefits, such as employer provided medical insurance, employer contributions to pension accounts, and employer share of payroll taxes. ${ }^{11}$ Using NIPA Table 1.12, we compute the ratio of supplements to wages and salaries (Table 1.12, line 6) to wage and salary accruals (line 3). Calling the ratio $b_{t}$, and letting $p c e_{t}$ be the NIPA personal consumption price index (Table 1.1.4), we set

$$
\overline{\ln \left(w_{s t}\right)} \equiv \ln \widetilde{\left(w_{s t}\right)}+\ln \left(1+b_{t}\right)-\ln \left(p c e_{t}\right)
$$

Census data on worker's education. We use IPUMS Census and IPUMS CPS data from www.ipums.org/ to determine the distribution of male education levels.

For working males, and for white working males, we determine fractions $\omega_{s t}(e)$ in education category $e \in \mathcal{E}$ for $s=29, \ldots, 60, t=1949, \ldots, 2004$. We use IPUMS Census data for 1950 and 1960, and IPUMS CPS data for 1962-2004 - linearly interpolating the missing years.

11 Notice that the Social Security tax base is almost the same as the base for the federal income tax - except for less than 100 percent participation in OASI and the Social Security tax cap. See, for example, CBO [2005]. 
BLS data on TFP growth. $\quad$ We use BLS data to derive $\ln \left(T_{t}\right)$ and $\ln \left(w_{t}^{E}\right)$ for $(9) .{ }^{12}$

From http://www.bls.gov/mfp/mprdload.htm, go to the "Historical Multifactor Productivity Measures" section. Opening the spreadsheet mfp_tables_historical.xls, find the tables for the private non-farm business sector. Table 2.1, col 2, provides measurements of $Y_{t} / K_{t}$; Table 4.2, col 5, provides the same for $T_{t}$. Although Table 4.1, col. 2, provides data 1948-2010 for $\alpha_{t}$, to stay in a standard framework we follow Gollin [2002] and others in setting $\alpha=0.25$.

5 Empirical Analysis. Our 2 empirical formulations both begin with (9).

Our SSA data average log earnings over individuals $i$ for each $($ age, time $)=(s, t)$ cell, and we want to perform such averaging for each term in (9). As in Section 4, let $\overline{\ln \left(w_{s t}\right)}$ be average log earnings for a given cell, corrected for benefits and the price index. Define $^{13}$

$$
\overline{\Delta \ln \left(w_{s t}\right)} \equiv \overline{\ln \left(w_{s t}\right)}-\overline{\ln \left(w_{s-1, t-1}\right)} .
$$

Similarly, letting a tilde designate an average over $i$,

$$
\left.\overline{\Delta \ln \left(H_{s}\right)} \equiv \ln \widetilde{\left(H_{s}\right.}\right)-\ln \left(\widetilde{H_{s-1}}\right) .
$$

As there is nothing to estimate in the last term of (9), the dependent variable in our regression analysis is

$$
\Delta \ln \left(W_{s t}\right) \equiv \overline{\Delta \ln \left(w_{s t}\right)}-\Delta \ln \left(w_{t}^{E}\right) .
$$

Our Census data enables us to compute the fraction of workers of age $s$ at time $t$ who have education $e$. As in Section 4, call the fraction $\omega_{s t}^{1}(e)$. Then

$$
\overline{\Delta \ln \left(H_{s}\right)}=\sum_{e \in \mathcal{E}} w_{s t}^{1}(e) \cdot p_{1}(e)+\sum_{e \in \mathcal{E}} w_{s t}^{2}(e) \cdot p_{2}(e)
$$

where

$$
\omega_{s t}^{2}(e) \equiv \omega_{s t}^{1}(e) \cdot[x(s, e)-0.5] .
$$

12 Earlier work with data from Fernald — see http://www.frbsf.org/csip/tfp.php and Basu et al. [2006] — did not yield different results.

13 To be precise, we have panel data - and we only use households in our log-differences that appear in both components of the difference. Thus, strictly speaking,

$\overline{\Delta \ln \left(w_{s t}\right)} \equiv \frac{\sum_{i} \ln \left(w_{i s t}\right)-\ln \left(w_{i, s-1, t-1}\right)}{\# i}+\ln \left(1+b_{t}\right)-\ln \left(1+b_{t-1}\right)-\ln \left(\right.$ pce $\left._{t}\right)+\ln \left(\right.$ pce $\left._{t-1}\right)$ 
Our second specification makes $p_{1}(e)$ and $p_{2}(e)$ independent of $e$. Under our third specification, we replace $\sum_{e \in \mathcal{E}} \omega_{s t}^{1}(e) \cdot p_{1}(e)$ with a constant and $x$ in $\omega_{s t}^{2}(e)$ with $s$.

In fact, the 3 possible specifications yield similar results for the other parts of our earnings dynamics equation. Hence, this paper reports results exclusively for an age-based specification.

In practice, we settle on a nonparametric approach. In place of $\overline{\Delta \ln \left(H_{s}\right)}$, we use a separate dummy $\beta_{s}$ for each age. This makes our key estimates, namely, $\theta_{S}$, independent of the human capital description. In other words, given the separate age dummies, subtracting the mean from $\Delta \ln \left(T_{t}^{*}\right)$ does not affect estimates of $\theta$, but it makes the regressors for $\beta_{s}$ and $\theta_{S}$ orthogonal to one another.

Formulation I. Our first regression equation is

$$
\Delta \ln \left(W_{s t}\right)=\beta_{s}+\theta_{S} \cdot \Delta \ln \left(T_{t}^{*}\right)+\epsilon_{s t},
$$

where we allow a separate $\theta_{S}$ each $S$, and a separate $\beta_{s}$ each $s$. The regression error is $\epsilon_{s t}$. The latter presumably reflects omitted variables, inaccuracies in the components of $w_{t}^{E}$, inaccuracies in the price discounting of wages and the attribution of benefits, the discrepancy between wage rates and earnings, etc. At this point, assume $\ln \left(T_{t}^{*}\right)$ on the right-hand side of (18) is accurately measured.

The top 3 panels of Table 1 provide information about the sample. As we would expect, the top panel shows faster earnings growth at young ages, where the percentage growth rate of experience is highest. Panel 2 shows more rapid earnings growth during 1950-69 than after. Comparing panels 2-3, we see a strong correlation between TFP and earnings growth.

Stacking the equations to pool the data, we obtain consistent estimates of $\beta_{s}$ and $\theta_{S}$. Table 2 presents the estimates of $\beta_{s}$ from samples with different age ranges. As is familiar from the literature, the estimates of $\beta_{s}$ display the pattern of an inverted parabola.

This paper's focus is $\theta_{S}$. The regression specification that we use henceforth is as follows. Define

$$
\begin{gathered}
\Delta^{*} \ln \left(W_{s t}\right) \equiv \Delta \ln \left(W_{s t}\right)-\frac{\sum_{s^{\prime}} \Delta \ln \left(W_{s, t^{\prime}}\right)}{\# t^{\prime}} \\
\Delta^{*} \ln \left(T_{t}^{*}\right) \equiv \Delta \ln \left(T_{t}^{*}\right)-\frac{\sum_{t^{\prime}} \Delta \ln \left(T_{t^{\prime}}^{*}\right)}{\# t^{\prime}}
\end{gathered}
$$

For each $s$, in other words, we subtract the mean (calculated over all $t$ ). Then

$$
\Delta^{*} \ln \left(W_{s t}\right)=\theta_{S} \cdot \Delta^{*} \ln \left(T_{t}^{*}\right)+\epsilon_{s t},
$$

where, of course, $S=S(s)$. OLS on (19) with pooled data yields the same parameter estimates, $\widehat{\theta}_{S}$, as separate regressions

$$
\Delta^{*} \ln \left(W_{s t}\right)=\theta_{S} \cdot \Delta^{*} \ln \left(T_{t}^{*}\right)+\epsilon_{s t} \quad \text { all } \quad t
$$

for each $s$. 
Table 1. Sample Information

\begin{tabular}{|c|c|c|c|c|}
\hline Variable & Mean & Coef. Var. & Min & Max \\
\hline \multicolumn{5}{|c|}{ Earnings data, $\Delta \ln \left(W_{\text {st }}\right), 1950-2004$} \\
\hline Ages 26-29 & 0.1395 & 0.2119 & 0.1021 & 0.1713 \\
\hline Ages 30-39 & 0.0790 & 0.6866 & -0.0085 & 0.1428 \\
\hline Ages 40-49 & 0.0489 & 0.9360 & -0.0356 & 0.0911 \\
\hline Ages 50-60 & 0.0377 & 1.0539 & -0.0332 & 0.0957 \\
\hline Ages 61-65 & 0.0269 & 1.8211 & -0.0504 & 0.0850 \\
\hline
\end{tabular}

Earnings data, $\Delta \ln \left(W_{\text {st }}\right)$, ages $30-60$

\begin{tabular}{|c|c|c|c|c|}
\hline Years 1950-1959 & 0.0477 & 1.0425 & -0.0525 & 0.1428 \\
\hline Years 1960-1969 & 0.0420 & 0.5214 & -0.0087 & 0.1022 \\
\hline Years 1970-1979 & 0.0255 & 1.6440 & -0.0524 & 0.1068 \\
\hline Years 1980-1989 & 0.0148 & 2.1208 & -0.0508 & 0.1081 \\
\hline Years 1990-2004 & 0.0255 & 0.9647 & -0.0365 & 0.1059 \\
\hline
\end{tabular}

Growth in BLS total factor productivity, $\Delta \ln \left(T_{t}^{*}\right)$

\begin{tabular}{|c|l|l|l|l|}
\hline Years 1950-1959 & 0.0252 & 1.2440 & -0.0182 & 0.0809 \\
\hline Years 1960-1969 & 0.0252 & 0.8177 & -0.0107 & 0.0491 \\
\hline Years 1970-1979 & 0.0145 & 2.0451 & -0.0459 & 0.0502 \\
\hline Years 1980-1989 & 0.0036 & 7.9824 & -0.0495 & 0.0487 \\
\hline Years 1990-2004 & 0.0154 & 0.8812 & -0.0130 & 0.0334 \\
\hline
\end{tabular}

Principal Components Estimate of TFP Growth, $\widehat{x}_{t}$ (Principal Components Vector for Data Sample with Ages 30-60)

\begin{tabular}{|c|c|c|c|c|}
\hline Years 1950-1959 & 0.0357 & 1.4548 & -0.0490 & 0.0874 \\
\hline Years 1960-1969 & 0.0297 & 0.6288 & 0.0005 & 0.0558 \\
\hline Years 1970-1979 & 0.0117 & 3.7706 & -0.0525 & 0.0597 \\
\hline Years 1980-1989 & -0.0012 & -24.7888 & -0.0515 & 0.0505 \\
\hline Years 1990-2004 & 0.0104 & 1.7403 & -0.0312 & 0.0381 \\
\hline
\end{tabular}


Table 2. Age-experience Profile of Earnings Growth

\begin{tabular}{|c|c|c|c|c|c|c|}
\hline \multirow{3}{*}{ Current Age } & \multicolumn{6}{|c|}{ Sample Age Range for Regression: } \\
\hline & \multicolumn{2}{|c|}{$30-60$} & \multicolumn{2}{|c|}{$26-60$} & \multicolumn{2}{|c|}{$26-65$} \\
\hline & $\beta_{s}$ & Cum. Total & $\beta_{s}$ & Cum. Total & $\beta_{s}$ & Cum. Total \\
\hline 26 & $\mathrm{NA}$ & $\overline{\mathrm{NA}}$ & 0.0821 & 0.0821 & 0.0821 & 0.0821 \\
\hline 27 & $\overline{\mathrm{NA}}$ & $\mathrm{NA}$ & 0.0716 & 0.1537 & 0.0716 & 0.1537 \\
\hline 28 & $\mathrm{NA}$ & $\mathrm{NA}$ & 0.0617 & 0.2154 & 0.0617 & 0.2154 \\
\hline 29 & $\overline{\mathrm{NA}}$ & $\mathrm{NA}$ & 0.0552 & 0.2706 & 0.0552 & 0.2706 \\
\hline 30 & 0.0481 & 0.0481 & 0.0481 & 0.3187 & 0.0481 & 0.3187 \\
\hline 31 & 0.0430 & 0.0912 & 0.0430 & 0.3617 & 0.0430 & 0.3617 \\
\hline 32 & 0.0396 & 0.1307 & 0.0396 & 0.4013 & 0.0396 & 0.4013 \\
\hline 33 & 0.0365 & 0.1672 & 0.0365 & 0.4378 & 0.0365 & 0.4378 \\
\hline 34 & 0.0325 & 0.1996 & 0.0325 & 0.4702 & 0.0325 & 0.4702 \\
\hline 35 & 0.0287 & 0.2283 & 0.0287 & 0.4989 & 0.0287 & 0.4989 \\
\hline 36 & 0.0269 & 0.2552 & 0.0269 & 0.5258 & 0.0269 & 0.5258 \\
\hline 37 & 0.0253 & 0.2805 & 0.0253 & 0.5511 & 0.0253 & 0.5511 \\
\hline 38 & 0.0228 & 0.3033 & 0.0228 & 0.5738 & 0.0228 & 0.5738 \\
\hline 39 & 0.0221 & 0.3253 & 0.0221 & 0.5959 & 0.0221 & 0.5959 \\
\hline 40 & 0.0190 & 0.3443 & 0.0190 & 0.6149 & 0.0190 & 0.6149 \\
\hline 41 & 0.0172 & 0.3615 & 0.0172 & 0.6321 & 0.0172 & 0.6321 \\
\hline 42 & 0.0144 & 0.3759 & 0.0144 & 0.6465 & 0.0144 & 0.6465 \\
\hline 43 & 0.0134 & 0.3894 & 0.0134 & 0.6600 & 0.0134 & 0.6600 \\
\hline 44 & 0.0118 & 0.4012 & 0.0118 & 0.6717 & 0.0118 & 0.6717 \\
\hline 45 & 0.0111 & 0.4123 & 0.0111 & 0.6828 & 0.0111 & 0.6828 \\
\hline 46 & 0.0084 & 0.4207 & 0.0084 & 0.6912 & 0.0084 & 0.6912 \\
\hline 47 & 0.0078 & 0.4285 & 0.0078 & 0.6990 & 0.0078 & 0.6990 \\
\hline 48 & 0.0062 & 0.4347 & 0.0062 & 0.7052 & 0.0062 & 0.7052 \\
\hline 49 & 0.0046 & 0.4393 & 0.0046 & 0.7098 & 0.0046 & 0.7098 \\
\hline 50 & 0.0063 & 0.4455 & 0.0063 & 0.7161 & 0.0063 & 0.7161 \\
\hline 51 & 0.0024 & 0.4479 & 0.0024 & 0.7185 & 0.0024 & 0.7185 \\
\hline 52 & 0.0019 & 0.4497 & 0.0019 & 0.7203 & 0.0019 & 0.7203 \\
\hline 53 & 0.0016 & 0.4513 & 0.0016 & 0.7219 & 0.0016 & 0.7219 \\
\hline 54 & 0.0005 & 0.4518 & 0.0005 & 0.7224 & 0.0005 & 0.7224 \\
\hline 55 & -0.0017 & 0.4501 & -0.0017 & 0.7207 & -0.0017 & 0.7207 \\
\hline 56 & -0.0032 & 0.4469 & -0.0032 & 0.7174 & -0.0032 & 0.7174 \\
\hline 57 & -0.0027 & 0.4442 & -0.0027 & 0.7148 & -0.0027 & 0.7148 \\
\hline 58 & -0.0048 & 0.4394 & -0.0048 & 0.7100 & -0.0048 & 0.7100 \\
\hline 59 & -0.0043 & 0.4351 & -0.0043 & 0.7057 & -0.0043 & 0.7057 \\
\hline 60 & -0.0054 & 0.4297 & -0.0054 & 0.7003 & -0.0054 & 0.7003 \\
\hline 61 & $\mathrm{NA}$ & $\mathrm{NA}$ & $\mathrm{NA}$ & $\mathrm{NA}$ & -0.0079 & 0.6924 \\
\hline 62 & $\overline{\mathrm{NA}}$ & $\mathrm{NA}$ & $\mathrm{NA}$ & $\mathrm{NA}$ & -0.0078 & 0.6846 \\
\hline 63 & NA & $\mathrm{NA}$ & $\mathrm{NA}$ & $\mathrm{NA}$ & -0.0154 & 0.6692 \\
\hline 64 & $\mathrm{NA}$ & NA & $\mathrm{NA}$ & $\mathrm{NA}$ & -0.0130 & 0.6562 \\
\hline 65 & $\mathrm{NA}$ & $\mathrm{NA}$ & $\mathrm{NA}$ & $\mathrm{NA}$ & -0.0247 & 0.6315 \\
\hline
\end{tabular}


We smooth our estimates using 3 -year moving averages. Let ${ }^{14}$

$$
\bar{\theta}_{S(s)} \equiv \frac{\theta_{S(s-1)}+\theta_{S(s)}+\theta_{S(s+1)}}{3}
$$

From (20),

$$
\frac{\Delta^{*} \ln \left(W_{s-1, t}\right)+\Delta^{*} \ln \left(W_{s t}\right)+\Delta^{*} \ln \left(W_{s+1, t}\right)}{3}=\bar{\theta}_{S(s)} \cdot \Delta^{*} \ln \left(T_{t}^{*}\right)+\frac{\epsilon_{s-1, t}+\epsilon_{s t}+\epsilon_{s+1, t}}{3}
$$

This is the equation that we estimate below.

Table 3 presents results. For each age $s$, we estimate (21) for all $t$. In other words, the estimating equations are separate each $s$. We use Discoll-Kraay [1998] standard errors. ${ }^{15}$

The first two age-range samples yield the same outcome: $\bar{\theta}_{S}$ falls $5-10 \%$ with age but the changes are not statistically significant with $95 \%$ confidence intervals. Extending the age range to 65 leads to outcomes for ages $64-65$ with no age-dependent change in $\bar{\theta}_{S}$. However, we suspect there may be a selection problem for workers in their mid-60s: those remaining in the labor force may be exceptional. Overall, we conclude that $\theta_{S}$ declines with $S$, but that the magnitude of the decline is modest.

Formulation II. Formulation II provides an alternative measure of TFP growth.

Suppose, for example, that $\theta_{1}>\theta_{60}$. Then the BLS measure of TFP growth is misspecified: the BLS constructs $L_{t}^{Q}$ - recall (5) - from numbers of workers of different ages and their relative wages at the given time $t$. But if $\theta_{1}>\theta_{60}$, relative wages at $t$ depend upon current and past TFP growth. We cannot rely upon an aggregated labor figure. Our model implies

$$
Y_{t}=\left[K_{t}\right]^{\alpha} \cdot\left[\sum_{i} \xi_{i} \cdot H_{i s} \cdot\left[T_{s-S}\right]^{\frac{1}{1-\alpha}} \cdot\left[\frac{T_{t-S+1}}{T_{s-S}}\right]^{\frac{\theta_{1}}{1-\alpha}} \cdot \ldots \cdot\left[\frac{T_{t}}{T_{t-1}}\right]^{\frac{\theta_{S}}{1-\alpha}}\right]^{1-\alpha}
$$

where we sum over all workers $i$ in the labor force at $t, s=s(i)$, and $S=S(s(i))$. Put another way, the effect of TFP growth on production depends upon the age distribution in a way that Solow's [1957] analysis of TFP does not encompass.

Formulation II proceeds as follows. We treat the true $\Delta^{*} \ln \left(T_{t}^{*}\right)$ as a latent variable,

$$
x_{t} \equiv \Delta^{*} \ln \left(T_{t}^{*}\right)
$$

For a given $s$, think of (20) as implying moment conditions

$$
\Delta^{*} \ln \left(W_{s t}\right)-\theta_{S(s)} \cdot x_{t}=0 \quad \text { all } \quad t=1950, \ldots, 2004
$$

14 At the lower endpoint, where $S=1$, we use $\left(2 \cdot \theta_{1}+\theta_{2}\right) / 3$, and similiarly at the upper endpoint.

15 See, in particular, the covariance matrix estimate corrected for heteroscedasticity and autocorrelation in Gallant [1987, ch.6, sect.3]. 
Table 3. Estimates of $\bar{\theta}_{s}$ from Eq. (21), Using BLS TFP Data

\begin{tabular}{|c|c|c|c|c|c|c|}
\hline \multirow{3}{*}{ Current Age } & \multicolumn{6}{|c|}{ Sample Age Range for Regression: } \\
\hline & \multicolumn{2}{|r|}{$30-60$} & \multicolumn{2}{|r|}{$26-60$} & \multicolumn{2}{|r|}{$26-65$} \\
\hline & $\bar{\theta}_{s}$ & $95 \%$ Conf. Int. & $\bar{\theta}_{s}$ & 95\% Conf. Int. & $\bar{\theta}_{s}$ & 95\% Conf. Int. \\
\hline 26 & NA & NA & 1.0171 & $(0.7784,1.2558)$ & 1.0171 & $(0.7784,1.2558)$ \\
\hline 27 & NA & NA & 1.0219 & $(0.7899,1.2540)$ & 1.0219 & $(0.7899,1.2540)$ \\
\hline 28 & NA & NA & 1.0152 & $(0.7921,1.2383)$ & 1.0152 & $(0.7921,1.2383)$ \\
\hline 29 & NA & $\mathrm{NA}$ & 1.0303 & $(0.8199,1.2407)$ & 1.0303 & $(0.8199,1.2407)$ \\
\hline 30 & 1.0329 & $(0.8250,1.2407)$ & 1.0290 & $(0.8197,1.2383)$ & 1.0290 & $(0.8197,1.2383)$ \\
\hline 31 & 1.0266 & $(0.8250,1.2282)$ & 1.0266 & $(0.8250,1.2282)$ & 1.0266 & $(0.8250,1.2282)$ \\
\hline 32 & 1.0176 & $(0.8140,1.2212)$ & 1.0176 & $(0.8140,1.2212)$ & 1.0176 & $(0.8140,1.2212)$ \\
\hline 33 & 1.0135 & $(0.8118,1.2151)$ & 1.0135 & $(0.8118,1.2151)$ & 1.0135 & $(0.8118,1.2151)$ \\
\hline 34 & 1.0246 & $(0.8216,1.2275)$ & 1.0246 & $(0.8216,1.2275)$ & 1.0246 & $(0.8216,1.2275)$ \\
\hline 35 & 1.0220 & $(0.8132,1.2307)$ & 1.0220 & $(0.8132,1.2307)$ & 1.0220 & $(0.8132,1.2307)$ \\
\hline 36 & 1.0100 & $(0.8051,1.2148)$ & 1.0100 & $(0.8051,1.2148)$ & 1.0100 & $(0.8051,1.2148)$ \\
\hline 37 & 0.9929 & $(0.7893,1.1965)$ & 0.9929 & $(0.7893,1.1965)$ & 0.9929 & $(0.7893,1.1965)$ \\
\hline 38 & 0.9954 & $(0.7902,1.2007)$ & 0.9954 & $(0.7902,1.2007)$ & 0.9954 & $(0.7902,1.2007)$ \\
\hline 39 & 0.9742 & $(0.7601,1.1884)$ & 0.9742 & $(0.7601,1.1884)$ & 0.9742 & $(0.7601,1.1884)$ \\
\hline 40 & 0.9998 & $(0.7894,1.2102)$ & 0.9998 & $(0.7894,1.2102)$ & 0.9998 & $(0.7894,1.2102)$ \\
\hline 41 & 1.0131 & $(0.8102,1.2160)$ & 1.0131 & $(0.8102,1.2160)$ & 1.0131 & $(0.8102,1.2160)$ \\
\hline 42 & 1.0673 & $(0.8650,1.2696)$ & 1.0673 & $(0.8650,1.2696)$ & 1.0673 & $(0.8650,1.2696)$ \\
\hline 43 & 1.0468 & $(0.8461,1.2475)$ & 1.0468 & $(0.8461,1.2475)$ & 1.0468 & $(0.8461,1.2475)$ \\
\hline 44 & 1.0508 & $(0.8428,1.2588)$ & 1.0508 & $(0.8428,1.2588)$ & 1.0508 & $(0.8428,1.2588)$ \\
\hline 45 & 1.0182 & $(0.8148,1.2215)$ & 1.0182 & $(0.8148,1.2215)$ & 1.0182 & $(0.8148,1.2215)$ \\
\hline 46 & 1.0214 & $(0.8214,1.2213)$ & 1.0214 & $(0.8214,1.2213)$ & 1.0214 & $(0.8214,1.2213)$ \\
\hline 47 & 1.0103 & $(0.8128,1.2077)$ & 1.0103 & $(0.8128,1.2077)$ & 1.0103 & $(0.8128,1.2077)$ \\
\hline 48 & 1.0227 & $(0.8179,1.2276)$ & 1.0227 & $(0.8179,1.2276)$ & 1.0227 & $(0.8179,1.2276)$ \\
\hline 49 & 0.9954 & $(0.7926,1.1982)$ & 0.9954 & $(0.7926,1.1982)$ & 0.9954 & $(0.7926,1.1982)$ \\
\hline 50 & 0.9893 & $(0.7827,1.1959)$ & 0.9893 & $(0.7827,1.1959)$ & 0.9893 & $(0.7827,1.1959)$ \\
\hline 51 & 0.9607 & $(0.7486,1.1729)$ & 0.9607 & $(0.7486,1.1729)$ & 0.9607 & $(0.7486,1.1729)$ \\
\hline 52 & 0.9815 & $(0.7687,1.1943)$ & 0.9815 & $(0.7687,1.1943)$ & 0.9815 & $(0.7687,1.1943)$ \\
\hline 53 & 0.9716 & $(0.7574,1.1858)$ & 0.9716 & $(0.7574,1.1858)$ & 0.9716 & $(0.7574,1.1858)$ \\
\hline 54 & 1.0002 & $(0.7914,1.2090)$ & 1.0002 & $(0.7914,1.2090)$ & 1.0002 & $(0.7914,1.2090)$ \\
\hline 55 & 1.0053 & $(0.7788,1.2318)$ & 1.0053 & $(0.7788,1.2318)$ & 1.0053 & $(0.7788,1.2318)$ \\
\hline 56 & 0.9980 & $(0.7807,1.2153)$ & 0.9980 & $(0.7807,1.2153)$ & 0.9980 & $(0.7807,1.2153)$ \\
\hline 57 & 0.9977 & $(0.7867,1.2086)$ & 0.9977 & $(0.7867,1.2086)$ & 0.9977 & $(0.7867,1.2086)$ \\
\hline 58 & 0.9839 & $(0.7772,1.1905)$ & 0.9839 & $(0.7772,1.1905)$ & 0.9839 & $(0.7772,1.1905)$ \\
\hline 59 & 0.9785 & $(0.7705,1.1865)$ & 0.9785 & $(0.7705,1.1865)$ & 0.9785 & $(0.7705,1.1865)$ \\
\hline 60 & 0.9441 & $(0.7384,1.1498)$ & 0.9441 & $(0.7384,1.1498)$ & 0.9532 & $(0.7558,1.1505)$ \\
\hline 61 & NA & NA & NA & NA & 0.9321 & $(0.7200,1.1441)$ \\
\hline 62 & NA & NA & NA & NA & 0.9276 & $(0.7077,1.1475)$ \\
\hline 63 & $\mathrm{NA}$ & $\mathrm{NA}$ & $\mathrm{NA}$ & $\mathrm{NA}$ & 0.9221 & $(0.6815,1.1627)$ \\
\hline 64 & $\mathrm{NA}$ & $\mathrm{NA}$ & NA & NA & 0.9658 & $(0.6984,1.2333)$ \\
\hline 65 & NA & NA & $\mathrm{NA}$ & NA & 1.0051 & $(0.6943,1.3158)$ \\
\hline
\end{tabular}


Using each $s$ in turn, and imposing $\theta_{1}=1,(22)$ can yield consistent estimates of $\theta_{S}$ all $S>1$ and $x_{t}$ all $t$. After all, each $\Delta^{*} \ln \left(W_{s t}\right)$ averages wage growth over a very large cross-section of workers.

Suppose that we extract the first principal component from

$$
\begin{gathered}
Y^{\prime} Y \\
Y \equiv\left[Y_{s t}\right]=\left[\Delta^{*} \ln \left(W_{s t}\right)\right] \text { all } s, t .
\end{gathered}
$$

If $\lambda$ is the largest eigenvalue of $Y^{\prime} Y$ and $c$ the corresponding eigenvector, the first principal component is $\widehat{x}$ with $^{16}$

$$
\begin{gathered}
Y c=\widehat{x}, \\
Y^{\prime} Y c=\lambda \cdot c .
\end{gathered}
$$

We can arrange the normalizations such that the first element of $c$ is 1 . The derivation of $c$ and $\widehat{x}$ mimics a method of moments estimation based upon (22) and cross-sectional data - using the identity matrix as the weighting matrix. So, we can think of our principal components estimates $c$ and $\widehat{x}$ as consistent estimates of $\theta$ and $x$.

A second interpretation of $c$ is as follows. Each element $c_{S}$ corresponds to the OLS estimate of $\theta_{S}$ from regression ${ }^{17}$

$$
Y_{s t}=\theta_{S(s)} \cdot \widehat{x}_{t}+\epsilon_{s t} \quad \text { all } t=1950, \ldots, 2004 .
$$

Letting the OLS estimate of $\theta_{S}$ be $\widehat{\theta}_{S}$, and letting $\widehat{\epsilon}_{s t}$ be the regression residual, a consistent estimate of the stardard error for $\sqrt{\# t} \cdot\left(\widehat{\theta}_{S}-\theta_{S}\right)$ is ${ }^{18}$

$$
\left[\frac{\widehat{x}^{\prime} \widehat{x}}{\# t}\right]^{-1} \cdot\left[\frac{\widehat{x}^{\prime} \widehat{\epsilon}^{\prime} \widehat{x}}{\# t}\right] \cdot\left[\frac{\widehat{x}^{\prime} \widehat{x}}{\# t}\right]^{-1} .
$$

We estimate the middle term with our Driscoll-Kraay procedure from Formulation I.

Table 4 presents outcomes. The new regression delivers smaller standard errors. As stated, we normalize the principal components vector such that $\theta_{1}=1$. Our first two samples, ages 30-60 and 25-60, yield declines in $\bar{\theta}_{S}$ with age in the range of $10-15 \%$. In contrast to Table 3, the declines are statistically significant. The sample for ages 25-65 shows a (slight) rebound in $\bar{\theta}_{S}$ at ages above 62 - presumably due to selection, as before.

16 See, for example, Greene [1993, p.271].

17 See Greene [1993] again. Note that (24)-(25) imply

$$
\theta^{\prime}=\left[\widehat{x}^{\prime} \widehat{x}\right]^{-1} \widehat{x}^{\prime} Y=\left[c^{\prime} Y^{\prime} Y c\right]^{-1} c^{\prime} Y^{\prime} Y=\left[c^{\prime} \cdot \lambda \cdot c\right]^{-1} \lambda \cdot c^{\prime}=\frac{c^{\prime}}{c^{\prime} c} .
$$

The standard normalization is $c^{\prime} c=1$, yielding $\theta^{\prime}=c^{\prime}$. As above, we renormalize $c$, and $\widehat{x}$, so that $\theta_{1}=1$.

18 See Bai and Ng [2006]. 
Table 4. Estimates of $\bar{\theta}_{s}$ from Eq. (26), Using Principal Components TFP Data

\begin{tabular}{|c|c|c|c|c|c|c|}
\hline \multirow{3}{*}{ Current Age } & \multicolumn{6}{|c|}{ Sample Age Range for Regression: } \\
\hline & \multicolumn{2}{|r|}{$30-60$} & \multicolumn{2}{|r|}{$26-60$} & \multicolumn{2}{|r|}{$26-65$} \\
\hline & $\bar{\theta}_{s}$ & 95\% Conf. Int. & $\bar{\theta}_{s}$ & 95\% Conf. Int. & $\bar{\theta}_{s}$ & 95\% Conf. Int. \\
\hline 26 & $\mathrm{NA}$ & NA & 0.9943 & $(0.9268,1.0618)$ & 0.9949 & $(0.9183,1.0714)$ \\
\hline 27 & $\mathrm{NA}$ & $\mathrm{NA}$ & 0.9937 & $(0.9371,1.0503)$ & 0.9952 & $(0.9295,1.0608)$ \\
\hline 28 & NA & NA & 0.9839 & $(0.9309,1.0369)$ & 0.9864 & $(0.9249,1.0480)$ \\
\hline 29 & NA & NA & 0.9803 & $(0.9334,1.0272)$ & 0.9833 & $(0.9307,1.0360)$ \\
\hline 30 & 1.0075 & $(0.9558,1.0592)$ & 0.9785 & $(0.9362,1.0209)$ & 0.9821 & $(0.9342,1.0300)$ \\
\hline 31 & 1.0026 & $(0.9615,1.0437)$ & 0.9739 & $(0.9385,1.0093)$ & 0.9775 & $(0.9346,1.0203)$ \\
\hline 32 & 0.9931 & $(0.9529,1.0332)$ & 0.9641 & $(0.9290,0.9991)$ & 0.9680 & $(0.9249,1.0111)$ \\
\hline 33 & 0.9871 & $(0.9423,1.0318)$ & 0.9575 & $(0.9182,0.9968)$ & 0.9616 & $(0.9128,1.0103)$ \\
\hline 34 & 0.9952 & $(0.9585,1.0319)$ & 0.9648 & $(0.9330,0.9966)$ & 0.9693 & $(0.9291,1.0095)$ \\
\hline 35 & 1.0027 & $(0.9663,1.0391)$ & 0.9713 & $(0.9390,1.0036)$ & 0.9763 & $(0.9361,1.0165)$ \\
\hline 36 & 0.9845 & $(0.9588,1.0102)$ & 0.9530 & $(0.9305,0.9756)$ & 0.9585 & $(0.9293,0.9878)$ \\
\hline 37 & 0.9755 & $(0.9504,1.0007)$ & 0.9439 & $(0.9226,0.9653)$ & 0.9503 & $(0.9215,0.9791)$ \\
\hline 38 & 0.9777 & $(0.9480,1.0074)$ & 0.9456 & $(0.9182,0.9730)$ & 0.9526 & $(0.9203,0.9849)$ \\
\hline 39 & 0.9688 & $(0.9205,1.0170)$ & 0.9373 & $(0.8924,0.9822)$ & 0.9446 & $(0.8935,0.9957)$ \\
\hline 40 & 0.9743 & $(0.9457,1.0029)$ & 0.9420 & $(0.9144,0.9695)$ & 0.9495 & $(0.9167,0.9823)$ \\
\hline 41 & 0.9671 & $(0.9431,0.9910)$ & 0.9352 & $(0.9135,0.9568)$ & 0.9428 & $(0.9141,0.9715)$ \\
\hline$\overline{42}$ & 0.9952 & $(0.9720,1.0184)$ & 0.9617 & $(0.9371,0.9864)$ & 0.9703 & $(0.9477,0.9930)$ \\
\hline 43 & 0.9762 & $(0.9510,1.0014)$ & 0.9437 & $(0.9189,0.9685)$ & 0.9519 & $(0.9253,0.9785)$ \\
\hline 44 & 0.9853 & $(0.9612,1.0094)$ & 0.9519 & $(0.9255,0.9784)$ & 0.9608 & $(0.9368,0.9847)$ \\
\hline 45 & 0.9540 & $(0.9208,0.9871)$ & 0.9216 & $(0.8884,0.9547)$ & 0.9297 & $(0.8948,0.9645)$ \\
\hline 46 & 0.9553 & $(0.9337,0.9768)$ & 0.9228 & $(0.9005,0.9451)$ & 0.9314 & $(0.9085,0.9542)$ \\
\hline 47 & 0.9412 & $(0.9106,0.9719)$ & 0.9094 & $(0.8793,0.9395)$ & 0.9183 & $(0.8875,0.9491)$ \\
\hline 48 & 0.9562 & $(0.9201,0.9922)$ & 0.9239 & $(0.8882,0.9597)$ & 0.9335 & $(0.8997,0.9673)$ \\
\hline 49 & 0.9333 & $(0.8929,0.9738)$ & 0.9015 & $(0.8610,0.9420)$ & 0.9108 & $(0.8713,0.9503)$ \\
\hline 50 & 0.9287 & $(0.8942,0.9631)$ & 0.8963 & $(0.8615,0.9311)$ & 0.9055 & $(0.8700,0.9411)$ \\
\hline 51 & 0.9063 & $(0.8607,0.9519)$ & 0.8742 & $(0.8289,0.9195)$ & 0.8835 & $(0.8357,0.9313)$ \\
\hline 52 & 0.9349 & $(0.8963,0.9735)$ & 0.9012 & $(0.8613,0.9411)$ & 0.9118 & $(0.8715,0.9522)$ \\
\hline 53 & 0.9333 & $(0.8926,0.9740)$ & 0.9000 & $(0.8573,0.9427)$ & 0.9108 & $(0.8700,0.9517)$ \\
\hline 54 & 0.9492 & $(0.9153,0.9831)$ & 0.9157 & $(0.8779,0.9534)$ & 0.9274 & $(0.8978,0.9569)$ \\
\hline 55 & 0.9290 & $(0.8622,0.9957)$ & 0.8961 & $(0.8293,0.9630)$ & 0.9076 & $(0.8447,0.9705)$ \\
\hline 56 & 0.9174 & $(0.8488,0.9860)$ & 0.8847 & $(0.8163,0.9530)$ & 0.8969 & $(0.8323,0.9614)$ \\
\hline 57 & 0.9218 & $(0.8708,0.9728)$ & 0.8881 & $(0.8352,0.9409)$ & 0.9006 & $(0.8533,0.9479)$ \\
\hline 58 & 0.9278 & $(0.8884,0.9671)$ & 0.8939 & $(0.8515,0.9364)$ & 0.9073 & $(0.8726,0.9420)$ \\
\hline 59 & 0.9178 & $(0.8814,0.9541)$ & 0.8844 & $(0.8447,0.9241)$ & 0.8980 & $(0.8663,0.9296)$ \\
\hline 60 & 0.8940 & $(0.8602,0.9278)$ & 0.8620 & $(0.8255,0.8984)$ & 0.8694 & $(0.8373,0.9016)$ \\
\hline 61 & NA & NA & $\mathrm{NA}$ & NA & 0.8679 & $(0.8276,0.9083)$ \\
\hline 62 & $\mathrm{NA}$ & $\mathrm{NA}$ & $\mathrm{NA}$ & $\mathrm{NA}$ & 0.8733 & $(0.8104,0.9362)$ \\
\hline 63 & NA & NA & NA & $\mathrm{NA}$ & 0.8789 & $(0.7953,0.9624)$ \\
\hline 64 & NA & NA & NA & $\mathrm{NA}$ & 0.8976 & $(0.7844,1.0108)$ \\
\hline 65 & $\mathrm{NA}$ & $\mathrm{NA}$ & $\mathrm{NA}$ & $\mathrm{NA}$ & 0.9220 & $(0.7792,1.0649)$ \\
\hline
\end{tabular}


The declines in $\theta_{S}$ that we see are gradual. By age 45 , about half of the eventual total drop has taken place. Thus, we do not see evidence that workers abruptly cease to invest in knowledge as they approach retirement. Total declines are rather modest in all cases though they now seem to fall in the range of $10-15 \%$.

The principal components vectors are themselves interesting. By comparing $\lambda$ with all other eigenvalues, we can compute the fraction of variance in the $Y^{\prime} Y$ matrix explained by the first principal component. For our 3 age ranges, the percentages are $96 \%, 96 \%$, and $93 \%$, respectively. We can derive the correlation coefficient for the principal components vector and the BLS vector $\Delta \ln \left(T_{t}^{*}\right)$. The correlation coefficients are $0.7643,0.7599$, and 0.7613 , respectively. The bottom panels of Table 1 present comparisons between the principal components vector for our age sample 30-60 and the BLS vector. We can see that the principal components analysis finds a faster rate of technological progress in the 1960s, and an appreciably faster rate in the 1950s, but it shows a modestly slower rate 1970-2004.

We view the high correlations in the preceding paragraph as confirmation of Solow's [1956,1957] approach. Solow assumes an aggregate production function and uses it to derive measures of TFP. Given his specification, the envelope theorem and the production function provide an avenue for deriving a second measure of TFP, which should correspond to the first. The high correlations that we find between $\widehat{x}_{t}$ and $\Delta \ln \left(T_{t}^{*}\right)$ show that there is indeed a strong correspondence.

On the other hand, the correlations are not 100\%, and we think that the principal components approach has advantages. In particular, the principal components approach avoids misspecifications that may result from imposing $\theta_{S}=1$ all $S$; it makes use of averages of large numbers of observations, yielding consistent estimates of yearly changes; and, it uses differenced observations from panel data. The last eliminates personal fixed effects stemming, for example, from inherent ability and education - which the BLS approach, based on cross-sectional data, may confound.

6 Interpretation of Results. Our estimates lead to a decomposition of the effective labor supply that can conveniently illustrate the effect of $\theta<1$ on aggregate earnings and also quantify the aggregate effects of an aging labor force.

Consider the interpretation of our empirical results in the context of a theoretical framework (5)-(7). Suppose that the TFP term $\left[T_{t}\right]^{\frac{1}{1-\alpha}}$ in (5) grows at a constant rate $g$ equal to the average growth rate of aggregate earnings. Disregard worker-specific ability $\xi_{i}$ because we will average over many $i$. Equation (7) shows that the wage $w_{S t}$ for a worker with labor market experience $S$ at time $t$ is

$$
w_{S t}=\left[T_{t}\right]^{\frac{1}{1-\alpha}} \cdot H_{S} \cdot[1+g]^{\sum_{x=1}^{S}\left(\theta_{x}-1\right)} \cdot w_{t}^{E} .
$$

Accordingly, the current earnings of a worker with experience $S$ relative to a new entrant to the labor force are

$$
\frac{w_{S t}}{w_{0 t}}=\frac{H_{S}}{H_{0}} \cdot[1+g]^{\sum_{x=1}^{S}\left(\theta_{x}-1\right)} .
$$

Section 5 provides estimates of $H_{S} / H_{0}$ (see Table 2) and the vector of $\theta_{x}$ (Tables 3 and 4). The value of $g=0.0167$ can be taken from BLS data on TFP growth. 
Age-earnings Profile. Figure 1 illustrates the quantitative impact of our estimates of $\theta$ on the age-earnings profile. The figure isolates the effect of $\theta$ on earnings by comparing two cross-sectional age-earnings profiles, $w_{S t} / w_{0 t}$ : the (counterfactual) upper profile corresponds to the case $\theta_{x}=1$, where workers of all ages receive the full earnings increment that results from TFP growth. The lower profile corresponds to actual estimates of $\theta_{x}$ from Table 4, column 5. The difference between the two profiles is earnings forgone due to incomplete absorption of technological progress by older workers. By age 65, an average worker will have lost about 2.6 years' worth of TFP-induced wage growth, which reduces his earnings by about 5 percent.

Labor Supply Decomposition. Consider the effect of $\theta$ on aggregate earnings.

Using (28) and letting

$$
N_{x}=N_{0} \cdot e^{-n x}
$$

be the size of a cohort with experience $x$, the aggregate effective labor supply is

$$
E_{t}=\frac{\sum_{x} w_{x t} \cdot N_{x}}{w^{E}}=\left[T_{t}\right]^{\frac{1}{1-\alpha}} \cdot \sum_{x} H_{x} \cdot N_{x} \cdot[1+g]^{\sum_{z=1}^{x}\left(\theta_{z}-1\right)} .
$$

The right hand side of the above expression can be decomposed:

$$
E_{t}=\left[T_{t}\right]^{\frac{1}{1-\alpha}} \cdot\left(\frac{\sum_{x} H_{x} \cdot N_{x} \cdot[1+g]^{\sum_{z=1}^{x}\left(\theta_{z}-1\right)}}{\sum_{x} H_{x} \cdot N_{x}}\right) \cdot\left(\frac{\sum_{x} H_{x} \cdot N_{x}}{\sum_{x} N_{x}}\right) \cdot \sum_{x} N_{x} .
$$

The first term, $\left[T_{t}\right]^{\frac{1}{1-\alpha}}$, captures labor augmenting technological change. The second term,

$$
a \equiv \frac{\sum_{x} H_{x} \cdot N_{x} \cdot[1+g]^{\sum_{z=1}^{x}\left(\theta_{z}-1\right)}}{\sum_{x} H_{x} \cdot N_{x}},
$$

is the age factor that reduces effective labor supply due to incomplete absorption of technological change by older workers. The value of $a$ is generally less than 1 , with $a=1$ when all $\theta_{x}=1$. Put differently, $1-a$ is the fraction of aggregate earnings forgone due to incomplete absorption of technological progress.

The third term,

$$
h \equiv \frac{\sum_{x} H_{x} \cdot N_{x}}{\sum_{x} N_{x}}
$$

is the experience factor, equal to average experiential human capital per worker.

Set the labor force growth rate $n=0.01 ; g=0.0167$; use $H_{S}$ from Table 2, column 7; and, use $\theta_{x}$ from Table 4 , column 5 . Then $a=0.984$, meaning that the aggregate labor supply is 1.6 percent less than it would have been if $\theta$ were 1 . 


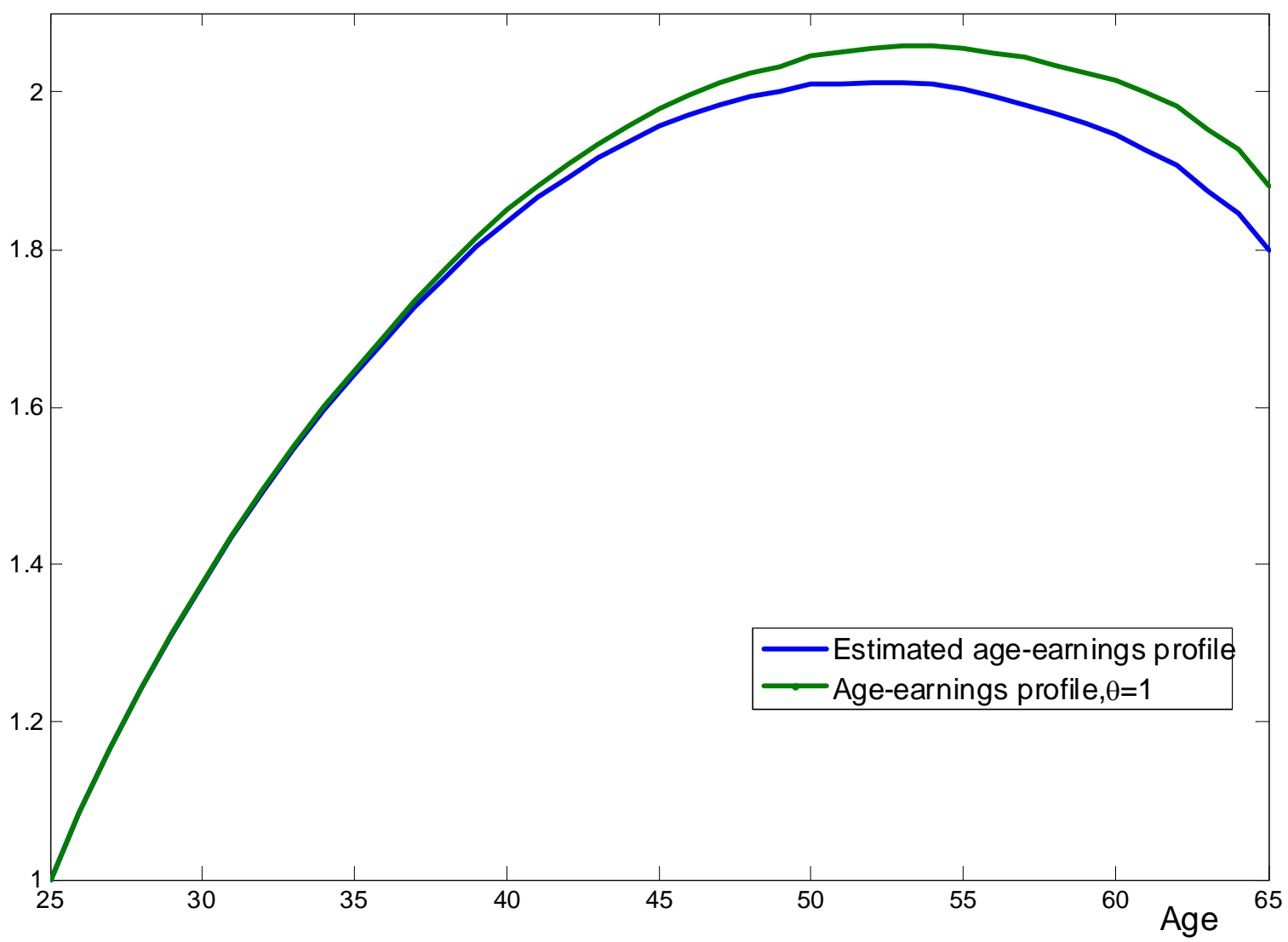

Figure 1. Age-earnings profile in a cross-section, $w_{x, t} / w_{0, t}$. 
Aging and Effective Labor Supply. To understand the effect of an aging labor force on the effective labor supply $E_{t}$, consider the dependence of the age factor $a$ and the experience factor $h$ on the labor force growth rate $n$. Suppose the underlying cause of an aging labor force is a reduction in population growth rate, $n$. Smaller population growth will shift the weights in (30) toward older cohorts, whose earnings are most affected by $\theta$, and this will reduce $a$ :

$$
\frac{\partial a}{\partial n}>0 .
$$

Figure 2 (top panel) illustrates the relationship for $n \in[-0.01,0.01]$. The effect of $n$ on the experience factor $h$ is ambiguous and depends on the shape of the experienceearnings profile $H_{S}$. If $H_{S}$ peaks at a relatively late age, a reduction in $n$ increases the weight of high-experience, high-earning workers, which increases $h$. If $H_{S}$ peaks early, older workers may have lower than average earnings, and then aging would decrease $h$. In practice, older workers have higher than average earnings (see Figure 1), making $h$ depend negatively on $n$ (see Figure 2, middle panel):

$$
\frac{\partial h}{\partial n}<0 .
$$

The total effect of aging on labor supply is a combination of the opposing effects on $a$ and $h$. In the end, the experience effect dominates, so that aging increases the effective labor supply - changing the labor force composition towards workers with more experiential human capital (Figure 2, bottom panel). The total effect of aging is relatively modest, however: if we reduce $n$ from 0.01 to 0 , the resulting increase in effective labor supply is about 1.4 percent.

7 Conclusions. We present an earnings dynamics model that allows technological progress to affect workers' marginal products, hence, their earnings, differentially at different ages. In one specification, we use a standard BLS measure of TFP growth as a regressor. In another, we derive a stand-in for aggregate TFP growth using principal components analysis.

We have access to a large panel of administrative data from the Social Security system. The data allow analysis for 1950-2004.

With BLS TFP data as a regressor, a 25-30 year old worker's earnings follow TFP growth 1-for-1, but a 60 year old worker's earnings climb, annually, only $90-95 \%$ as fast as TFP.

Our principal components approach - which essentially treats TFP as a latent variable - yields generally tighter standard errors. The measured declining-with-age ability to benefit from TFP growth is also somewhat more severe - registering a drop of 10-15\% by age 60 .

In all cases, however, simulated aging of the labor force through slower population growth yields (modest) net gains in aggregative labor efficiency: the growth in earnings from accumulating experience more than compensates for declines in ability to benefit from improvements in technology.

Our analysis examines one aspect of how a worker's marginal productivity is likely to fare as the individual ages. We do not study participation rates - though we note 

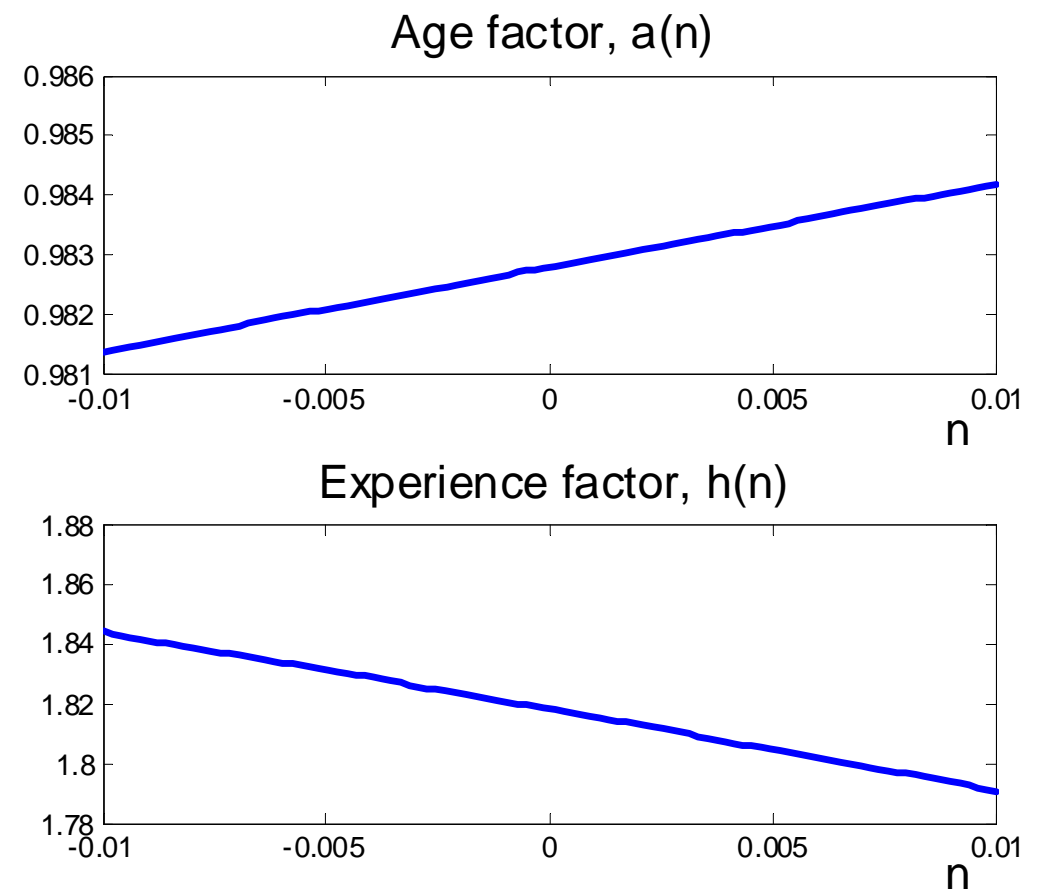

Age and experience factors combined, $a(n) h(n)$

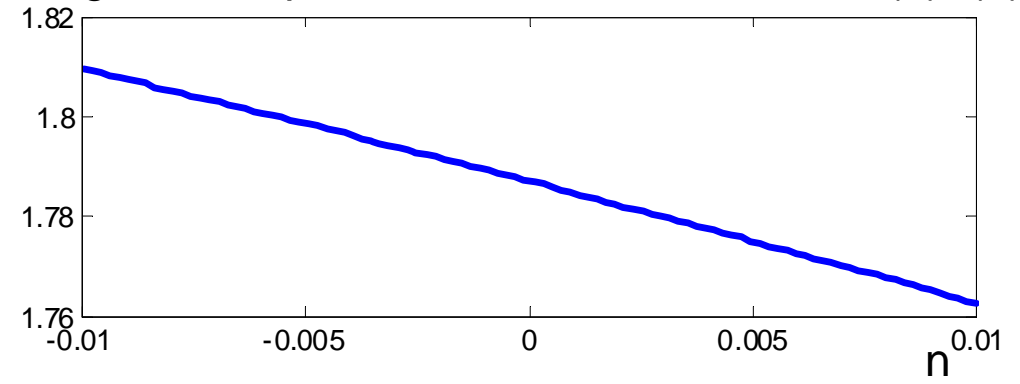

Figure 2. The dependence of age and experience factors on the labor force growth rate. 
that lost earnings due to declines in $\theta_{x}$ may lower remuneration around the average age of retirement by about $5 \%$. Increases in longevity presumably encourage workers to consider longer careers, but declines in $\theta_{x}$ will be one adverse factor - and this factor will become more important during eras of rapid technological change. 


\section{References}

[1] Altonji, Joseph G.; Smith, Anthony; and Vidangos, Ivan. (2009). "Modeling earnings dynamics," NBER Working Paper 14743.

[2] Altonji, Joseph G., and Williams, N. (1998). "The effects of labor market experience, job seniority, and mobility on wage growth," Research in Labor Economics 17, 233-276.

[3] Bai, Jushan, and Serena Ng, "Confidence Intervals for Diffusion Index Forecasts and Inference for Factor-Augmented Regressions," Econometrica 74, no. 4 (July 2006): $1133-1150$.

[4] Baily, Martin Neil, and Robert M. Solow (2001). "International Productivity Comparisons Built from the Firm Level," Journal of Economic Perspectives 15(3), 151-172.

[5] Baker, Michael. (1997). "Growth-rate heterogeneity and the covariance structure of life cycle earnings," Journal of Labour Economics 15(2), 338-375.

[6] Baker, Michael, and Solon, Gary. (2003). "Earnings dynamics and inequality among Canadian men, 1976-1992: Evidence from longitudinal income tax records," Journal of Labor Economics 21, 289-321.

[7] Basu, Susanto; Fernald, John G.; and Miles S. Kimball, "Are Technology Improvements Contractionary?" American Economic Review 96, no. 5 (December 2006): 1418-1448.

[8] Ben-Porath, Yoram, (1967). "The Production of Human Capital and the Life Cycle of Earnings." Journal of Political Economy 75, 352-365.

[9] Borsch-Supan, Axel, (2004). "Global Aging: Issues, Answers, More Questions." Working Paper WP 2004-084, University of Michigan Retirement Research Center. [www.mrrc.isr.umich.edu]

[10] Bound, John, Charles Brown, and Nancy Mathiowetz, 2001, "Measurement Error in Survey Data." Chapter in Handbook of Econometrics, V. 5, eds. E. E. Leamer and J. J. Heckman, pp. 3705-3843.

[11] Bound, John, and Alan B. Krueger, 1991. "The Extent of Measurement Error in Longitudinal Earnings Data: Do Two Wrongs Make a Right?" Journal of Labor Economics 9: 1-24.

[12] Burtless, Gary, and Quinn, Joseph, "Is Working Longer the Answer for An Aging Workforce?" Center for Retirement Research at Boston College Issue In Brief no. 11, 28.

[13] Congressional Budget Office, "Differences in Wage and Salary Income Included in Various Tax Bases," Background Paper, June 2005.

[14] Driscoll, John C., and Aart C. Kraay, "Consistent Covariance Matrix Estimation with Spatially Dependent Panel Data," The Review of Economics and Statistics 80(4) (November 1998): 549-560.

[15] Farber, H. (1999). "Mobility and stability: The dynamics of job change in labor markets," in O. Ashenfelter and D. Card, eds., Handbook of Labor Economics vol 3, part 2, 2439-2483. 
[16] Gallant, A. Ronald, Nonlinear Statistical Models. New York: John Wiley \& Sons, 1987.

[17] Goda, Gopi Shah; Shoven, John; and Slavov, Sita. (2009). "Removing the Disincentives in Social Security for Long Careers," in Jeffrey Brown, Jeffrey Liebman, and David Wise (eds.), Social Security Policy in a Changing Environment. University of Chicago Press.

[18] Gollin, Douglas, "Getting Income Shares Right," Journal of Political Economy 110, 2 (April 2002): 458-474.

[19] Greene, William H. Econometric Analysis, second ed. New York: Macmillan Publishing, 1993.

[20] Guvenen, F. (2007). "Learning your earning: Are labor income shocks really very persistent?" American Economic Review 97(3), 687-712.

[21] Haider, S.J. (2001). "Earnings instability and earnings inequality of males in the United States: 1967-1991," Journal of Labor Economics 19(4), 799-836.

[22] Haider, Steven, and Gary Solon, 2006. "Life-Cycle Variation in the Association between Current and Lifetime Earnings," American Economic Review 96(4): 1308-1320.

[23] Kopczuk, Wojciech, Emmanuel Saez and Jae Song. "Earnings Inequality and Mobility in the United States: Evidence from Social Security Data Since 1937," The Quarterly Journal of Economics (2010), 125(1): 91-128.

[24] Kopczuk et al. Web Appendix.

http://elsa.berkeley.edu/ saez/kopczuk-saez-songQJE10online_appendix.pdf.

[25] Laitner, John, and Silverman, Dan. (2012). "Consumption, Retirement and Social Security: Evaluating the Efficiency of Reform that Encourages Longer Careers," Journal of Public Economics, to appear.

[26] Laitner, John, and Stolyarov, Dmitriy. (2005). "Technological Progress and Worker Productivity at Different Ages," Michigan Retirement Research Center Working Paper 2005-107.

[27] Kambourov, G., and Manovskii, I. (2009). "Occupation Specificity of Human Capital," International Economic Review 83(4), 685-709.

[28] Lazear, E. P. (1979). "Why Is There Mandatory Retirement?" Journal of Political Economy 87 (6), 1261-1264.

[29] Lazear, E. P. (1981). "Agency, Earnings Profiles, Productivity, and Hours Restrictions," American Economic Review 71 (4), 606-620.

[30] Lillard, L., and Weiss, Y. (1979). "Components of variation in panel earnings data: American scientists 1960-70," Econometrica 47(2), 437-454.

[31] Lillard, L., and Willis, R. (1978). "Dynamic aspects of earning mobility," Econometrica $46(5), 985-1012$.

[32] MaCurdy, T.E. (1982). "The use of time series processes to model the error structure of earnings in a longitudinal data analysis," Journal of Econometrics 18, 83-114. 
[33] Moore, Jeffrey C., Linda L. Stinson, and Edward J. Welniak, Jr., 1997. "Income Measurement Error in Surveys: A Review," U.S. Census Bureau Research Report SM97/05.

[34] Nyce, Steven A., and Schieber, Sylvester J. The Economic Implications of Aging Societies. Cambridge: Cambridge University Press, 2005.

[35] Solow, Robert M., "A Contribution to the Theory of Economic Growth," Quarterly Journal of Economics 70, no. 1 (February 1956): 65-94.

[36] Solow, Robert M., "Technical Change and the Aggregate Production Function," Review of Economics and Statistics 39, no. 3 (August 1957): 312-320.

[37] Solow, Robert M., "Investment and Technological Progress," in Kenneth Arrow, Samuel Karlin, and Patrick Suppes, eds., Mathematical Methods in the Social Sciences 1959. Stanford, CA: Stanford University Press, 1960. 